\title{
Attempted control of hyperglycemia during cardiopulmonary bypass fails to improve neurologic or neurobehavioral outcomes in patients without diabetes mellitus undergoing coronary artery bypass grafting
}

\author{
John Butterworth, MD, ${ }^{\text {a }}$ Lynne E. Wagenknecht, $\mathrm{DrPH}^{\mathrm{b}}{ }^{\mathrm{C}}$ Claudine Legault, PhD, ${ }^{\mathrm{b}}$ Daniel J. Zaccaro, MS, ${ }^{\text {b* }}$
} Neal D. Kon, MD, ${ }^{c}$ John W. Hammon, Jr, MD, ${ }^{c}$ Anne T. Rogers, MBChB, ${ }^{a * *}$ B. Todd Troost, MD, ${ }^{d}$ David A. Stump, PhD, Curt D. Furberg, MD, PhD, and Laura H. Coker, $\mathrm{PhD}^{\mathrm{d}}$

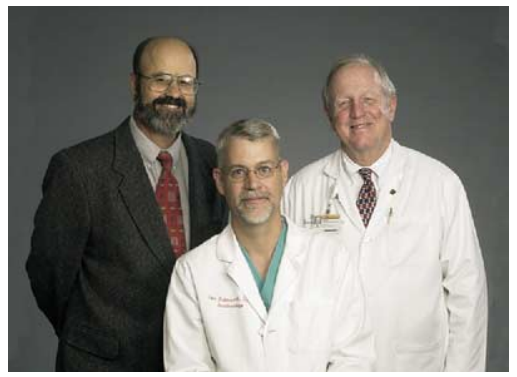

Stump, Butterworth (seated), Hammon

\section{Additional material} is available online.
From the Departments of Anesthesiology, Public Health Sciences, ${ }^{\text {b }}$ Cardiothoracic Surgery, ${ }^{c}$ and Neurology, ${ }^{\mathrm{d}}$ Wake Forest University School of Medicine, WinstonSalem, NC.

Received for publication Sept 15, 2004; revisions received Dec 8, 2004; accepted for publication Feb 28, 2005.

Address for reprints: John Butterworth, MD, Department of Anesthesiology, Wake Forest University School of Medicine, Medical Center Blvd, Winston-Salem, NC 27157-1009 (E-mail: jfbivjbutter@yahoo.com).

*Mr Zaccaro is currently affiliated with Rho, Inc, Chapel Hill, NC.

**Dr Rogers is currently affiliated with Atlantic Anesthesia, Virginia Beach, Va.

J Thorac Cardiovasc Surg 2005;130:1319-25

0022-5223/\$30.00

Copyright (C) 2005 by The American Association for Thoracic Surgery

doi:10.1016/j.jtcvs.2005.02.049
Objective: Hyperglycemia worsens outcomes in critical illness. This randomized, double-blind, placebo-controlled clinical trial tested whether insulin treatment of hyperglycemia during cardiopulmonary bypass would reduce neurologic, neuroophthalmologic, and neurobehavioral outcomes after coronary artery bypass grafting.

Methods: Three hundred eighty-one nondiabetic patients undergoing isolated coronary artery bypass grafting were given infusions of insulin or placebo when their blood glucose concentration exceeded $100 \mathrm{mg} / \mathrm{dL}$ during cardiopulmonary bypass. The primary outcome measure was the combined incidence of new neurologic, neuro-ophthalmologic, or neurobehavioral deficits or neurologic death observed at 4 to 8 days postoperatively. This same measure was assessed secondarily at 6 weeks and 6 months. Length of hospital stay was also compared as a secondary assessment.

Results: The 2 groups were well matched at baseline. The insulin-treated group had significantly lower blood glucose concentrations during bypass. Sixty-six percent of subjects in the insulin-treated group and $67 \%$ of subjects in the control group demonstrated a new or worsening neurologic, neuro-ophthalmologic, or neurobehavioral deficit or neurologic death at the 4- to 8-day assessment. Outcomes were also similar in the 2 groups at 6 weeks (37\% and 39\% incidence, respectively) and 6 months (30\% and 25\%, respectively). Median lengths of stay were 7 and 6 days, respectively, in the treatment and control groups. None of these outcome differences was statistically significant.

Conclusion: Attempted control of hyperglycemia during cardiopulmonary bypass had no significant effect on the combined incidence of neurologic, neuro-ophthalmologic, or neurobehavioral deficits or neurologic death and failed to shorten the length of hospital stay. These results do not contradict those of other studies showing that aggressive control of hyperglycemia in the postoperative period will improve outcome.

A fter coronary artery bypass grafting $(\mathrm{CABG})$ with cardiopulmonary bypass (CPB), $6 \%$ of patients have adverse neurologic outcomes. ${ }^{1}$ In the past, at least $50 \%$ of patients undergoing CPB displayed at least temporary deterioration in psychomotor performance, and a similar fraction of patients demonstrated biochemical evidence of neural injury. ${ }^{2,3}$ The incidence of frank stroke has been as frequent as $5 \%$ in some series. ${ }^{2}$ Despite continuing investigation, fundamental questions remain unanswered. One of these questions, that of the value of prevention of hyperglycemia during $\mathrm{CPB}$, was prompted by evidence linking adverse outcomes to intraoperative embolism 
and hyperglycemia to worsening ischemic neurologic injury. ${ }^{4,5}$ We therefore performed a randomized clinical trial in nondiabetic patients undergoing CABG to determine whether attempting to control hyperglycemia during $\mathrm{CPB}$ with insulin infusion, compared with placebo infusion, would reduce the combined incidence of new post-CABG neurologic, neuroophthalmologic, and neuropsychologic deficits. Secondarily, we sought to determine whether attempted blood glucose control during CPB would reduce the length of postoperative hospital stay. Some results unrelated to the primary hypothesis of this trial have been reported previously. ${ }^{6-8}$

\section{Methods}

The study was reviewed and approved by the Wake Forest University School of Medicine Institutional Review Board. Written informed consent was obtained from each prospective research subject. All subjects were English-speaking adults between the ages of 35 and 80 years scheduled to undergo CABG with CPB. Subjects with a history of diabetes mellitus treated by diet, oral hypoglycemic agents, or insulin were excluded. Subjects with a history of a neurodegenerative disease (eg, Alzheimer or Parkinson disease), major depressive disorder, or psychosis in the past 5 years were also excluded. Subjects underwent a neurologic and neuro-ophthalmologic history and physical examination and also underwent neuropsychologic testing on the afternoon or evening before the operation. These examinations usually were conducted in the patient's hospital room by one of two nurse clinicians. Generally, the same examiner conducted all examinations of a given subject.

\section{Day of the Operation}

All subjects were premedicated with morphine, $0.1 \mathrm{mg} \cdot \mathrm{kg}^{-1}$ administered intramuscularly, and, in most cases, oral lorazepam, $50 \mu \mathrm{g} \cdot \mathrm{kg}^{-1}$. Anesthesia consisted of intravenous fentanyl, 25 to $50 \mu \mathrm{g} \cdot \mathrm{kg}^{-1}$, and midazolam, 0.1 to $0.3 \mathrm{mg} \cdot \mathrm{kg}^{-1}$. After neuromuscular blockade (in most cases intravenous pancuronium, 0.1$0.15 \mathrm{mg} \cdot \mathrm{kg}^{-1}$ ), intubated subjects were ventilated with oxygenenriched air. Enflurane at inhaled concentrations of $1 \%$ or less was sometimes used to supplement general anesthesia. Intraoperative hemodynamic aberrations were treated according to protocol with intravenous fluid, vasodilators, vasoconstrictors, positive inotropes, atropine, or $\beta$-adrenergic blockers, as appropriate. No intravenous dextrose was administered intraoperatively on a routine basis. Dextrose was present in cardioplegic solutions (see Table E1). Corticosteroids were not administered to these patients.

\section{Blood Glucose Control}

Arterial blood samples were obtained at 15-minute intervals during CABG to measure blood glucose concentrations with a handheld glucose meter (Accucheck; Roche Diagnostics, Basel, Switzerland). In the control arm, blood glucose concentrations were measured and recorded for later analysis. A saline infusion was periodically adjusted to preserve blinding. For subjects randomized to blood glucose control, after induction of anesthesia, insulin infusion at $2 \mathrm{U} / \mathrm{h}$ in a $70-\mathrm{kg}$ patient was started when the blood glucose concentration exceeded $100 \mathrm{mg} / \mathrm{dL}$. If $2 \mathrm{U} / \mathrm{h}$ failed to reduce the blood glucose concentration to approximately $100 \mathrm{mg} / \mathrm{dL}$, the dosage was increased by $50 \%$ (to $3 \mathrm{U} / \mathrm{h}$ ) or $100 \%$ of the beginning dose (to $4 \mathrm{U} / \mathrm{h}$ ). Insulin infusion was adjusted as required at 15-minute intervals by the study nurse. Only the study nurse was aware of the glucose concentrations or whether insulin was being infused. When blood glucose concentrations decreased to less than $100 \mathrm{mg} / \mathrm{dL}$, the insulin infusion was discontinued. When blood glucose concentrations decreased to less than $70 \mathrm{mg} / \mathrm{dL}, 100$ to $200 \mathrm{~mL}$ of dextrose $5 \%$ was administered at the direction of the study nurse. After the patient was weaned from CPB, the insulin infusion was weaned over 30 to 45 minutes. Serum potassium concentrations were measured every 30 minutes intraoperatively and were maintained between 3.5 and $5.5 \mathrm{mEq} / \mathrm{L}$.

$\mathrm{CPB}$ was conducted with a membrane oxygenator and a buffered crystalloid priming solution to which no glucose was added. Mean arterial pressure was pharmacologically maintained between 50 and $90 \mathrm{~mm} \mathrm{Hg}$. Subjects were cooled to a core temperature of $27^{\circ} \mathrm{C}$ and then rewarmed to $37.5^{\circ} \mathrm{C}$. The left ventricle was vented through the right superior pulmonary vein, and the aorta was vented (when indicated) through a needle vent. Arterial inflow and cardiotomy suction filters were used. $\mathrm{PaO}_{2}$ was maintained at 150 to $200 \mathrm{~mm} \mathrm{Hg}$, and $\mathrm{PaCO}_{2}$ was maintained at 38 to $42 \mathrm{~mm} \mathrm{Hg}$ by the alpha-stat approach. Either crystalloid or (more commonly) blood cardioplegic solution was delivered antegradely. Cardioplegia components are described in Table E1. During rewarming, the inflow blood temperature never exceeded $38.5^{\circ} \mathrm{C}$, and the gradient between inflow blood temperature and core temperature never exceeded $10^{\circ} \mathrm{C}$.

\section{Outcome Measurement Timing}

A brief screening neurologic examination was conducted to document neurologic events that occurred on postoperative days 1 to 4. Subjects underwent a final, in-hospital, full neurologic, neuroophthalmologic, and neuropsychologic evaluation between postoperative days 4 and 8 . Subjects underwent the full neurologic, neuro-ophthalmologic, and neuropsychologic battery at 1 month (3-6 weeks) and again at 5.5 to 6.5 months. This testing took place in a quiet office.

\section{Primary Outcome}

The primary outcome variable used to define treatment effect in this clinical trial was any new or worsening neurologic or neuroophthalmologic deficit, neurologic death, or a decrease of at least $20 \%$ in 2 or more neuropsychologic test results at the 4 - to 8-day postoperative examination.

\section{Comprehensive Neurologic Examination}

The comprehensive neurologic and neuro-ophthalmologic examination was performed by a certified neurologic nurse clinician and confirmed by a neurologist. On postoperative days 4 to 8 , at 3 to 6 weeks, and at 5.5 to 6.5 months postoperatively, the entire neurologic examination was repeated, and results were scored according to the National Institutes of Health stroke scale and Stroke Data Bank criteria. $^{9}$

\section{Neuropsychologic Assessment}

We defined clinically important deterioration in performance as an individual subject's decrease from preoperative to postoperative score of $20 \%^{10,11}$ on a test. Neuropsychologic evaluation was 
performed preoperatively, on postoperative days 4 to 8 , at 3 to 6 weeks, and at 5.5 to 6.5 months. The standard neuropsychologic battery was used.

The Visual Reaction Time test was used only to discriminate between deterioration in performance because of ischemic neurologic deficits from deterioration caused by visual impairment.

\section{Sample Size Calculations}

We anticipated that at least $50 \%$ of the patients would experience one or more of these deficits at the 4- to 8-day assessment. A sample size of 186 in each group was necessary to detect a $17 \%$ difference in deficits $(0.5$ to 0.33 or 0.5 to 0.67$)$ with $90 \%$ power at the $5 \%$ 2-sided level of significance.

Patients were randomized to the treatment groups with equal probability by blocked randomization. Block sizes of varying length were determined randomly. Treatment assignments were generated by a randomization computer program.

\section{Statistical Testing}

The primary outcome was compared in the 2 groups by the Fisher exact test or the $\chi^{2}$ test where appropriate. Blood glucose measurements were compared over time by a mixed-effects, repeatedmeasures model. SAS (version 8; SAS Institute, Cary, NC) was used for all calculations.

\section{Interim Monitoring}

An independent Data Safety and Monitoring Board met once a year to examine interim results. Statistical guidelines (on the basis of modifications of procedures discussed by O'Brien and Fleming $^{12}$ and Lan and colleagues ${ }^{13}$ ) were used during the interim reviews.

\section{Results}

A total of 381 subjects completed preoperative screening and neuropsychologic evaluations and were enrolled in the study. The 2 groups were well matched on the basis of sex, age, and race, as shown in Table 1. Subjects in the 2 study groups were distributed similarly by operating surgeon (Table 1).

Baseline medical characteristics were similar in the 2 groups, with the exception of a more frequent history of congestive heart failure in the insulin-treated group $(9.6 \%$ vs $4.2 \%$ ). A history of cerebrovascular disease was present in $16.6 \%$ of placebo-treated patients and $15.4 \%$ of insulintreated patients. Five percent of patients in both groups demonstrated a stenosis of greater than $50 \%$ in one or more of the right or left, internal, or common carotid arteries by Doppler examination. The preoperative neuropsychologic examination scores were similar in the 2 treatment arms. There were no significant between-group differences (Table E2). Few subjects in either group had preoperative neuroophthalmologic or neurologic abnormalities (Table E3).

The duration of CPB (121 \pm 36 vs $125 \pm 37$ minutes $)$ and the duration of aortic clamping $(57 \pm 22$ vs $59 \pm 22$ minutes) were similar in the placebo- and insulin-treated groups, respectively. Most patients (80\% of placebo-treated and $82 \%$ of insulin-treated patients) received blood cardioplegia. The remainder received crystalloid cardioplegia.

All patients in the insulin-treated group demonstrated a blood glucose concentration of greater than $100 \mathrm{mg} / \mathrm{dL}$ and received insulin. Blood glucose concentrations were maintained at significantly $(P<.01)$ reduced values in the insulin-treated group compared with those in the placebotreated group, as shown in Figure 1. Initial blood glucose concentrations on arrival in the intensive care unit (ICU) were similar in the placebo-treated and insulin-treated groups (179 \pm 60 vs $178 \pm 57 \mathrm{mg} / \mathrm{dL}$, respectively). One patient in the placebo-treated group and no patients in the insulin-treated group had a blood glucose measurement of less than $80 \mathrm{mg} / \mathrm{dL}$ in the first 24 hours in the ICU. During the first 24 hours in the ICU, all patients had a blood glucose measurement of at least $100 \mathrm{mg} / \mathrm{dL}$. Many patients had at least one blood glucose measurement of greater than 200 $\mathrm{mg} / \mathrm{dL}$ (placebo-treated group, 40\%; insulin-treated group, $42 \%$ ). Only a few patients had at least one blood glucose measurement of greater than $300 \mathrm{mg} / \mathrm{dL}$ (placebo-treated group, 8\%; insulin-treated group, 6\%). One percent of patients in both groups had at least one blood glucose measurement of greater than $400 \mathrm{mg} / \mathrm{dL}$ during the first 24 hours in the ICU.

Most adverse events (including death) had a similar incidence in the 2 groups (Table 2). During postoperative evaluations, the 2 groups were similar (Table 3). Neuroophthalmologic, neurologic, and neuropsychologic deficits were most common at the 4- to 8-day examination and less common thereafter (Table 4). There was no significant between-group difference in the primary outcome (Table 4).

Length of stay was similar in the 2 groups (median of 6 days and range of 3-85 days in the placebo-treated group and median of 7 days and range of 3-51 days in the insulintreated group). The total number of emboli counted ultrasonically in the left common carotid artery was similar in the 2 groups (median of 105 and range of 1-2563 in the placebo-treated group and median of 108 and range of $1-14,613$ in the insulin-treated group).

To determine whether increasing blood glucose concentrations per se might associate with worsening neurologic outcomes, we divided subjects in the placebo-treated group into 2 equal classes on the basis of the degree of hyperglycemia they demonstrated during CPB. The cutoff point between the 2 groups was determined by calculating the area under the blood glucose versus time curve for each placebo-treated subject and then rank ordering them. We found that subjects ranked in the upper $50 \%$ of ranks for areas under the curve (these were the patients with more consistently increased blood glucose measurements) were no more likely than those in the lower $50 \%$ of ranks to have new or worsening neurologic, neurophthalmologic, or neurobehavioral deficit or neurologic death $(68 \%$ vs $71 \%$ at $4-8$ 
TABLE 1. Patient characteristics and distribution by treatment arm

\begin{tabular}{|c|c|c|c|c|c|}
\hline & $\begin{array}{c}\text { Placebo } \\
(n=193)^{*}\end{array}$ & $\begin{array}{c}\text { Insulin } \\
(\mathbf{n}=\mathbf{1 8 8})^{*}\end{array}$ & $\begin{array}{c}\text { All } \\
(n=381)\end{array}$ & $\begin{array}{c}P \text { value, } \\
\chi^{2}\end{array}$ & $\begin{array}{c}P \text { value, } \\
\text { Fisher exact test }\end{array}$ \\
\hline \multicolumn{6}{|l|}{ Sex } \\
\hline Male & $158(82)$ & $150(80)$ & $308(81)$ & .61 & .70 \\
\hline Female & $35(18)$ & $38(20)$ & $73(19)$ & & \\
\hline \multicolumn{6}{|l|}{ Race } \\
\hline White & $183(95)$ & $180(96)$ & $363(95)$ & .48 & $.62^{*}$ \\
\hline Black & $10(5)$ & $7(4)$ & $17(5)$ & & \\
\hline \multicolumn{6}{|l|}{ Age (y) } \\
\hline 50 & $29(15)$ & $34(18)$ & $63(17)$ & .56 & \\
\hline $51-60$ & $57(30)$ & $53(28)$ & $110(29)$ & & \\
\hline $61-70$ & $73(38)$ & $61(32)$ & $134(35)$ & & \\
\hline$>70$ & $34(18)$ & $40(21)$ & 74 (19) & & \\
\hline \multicolumn{6}{|l|}{ Surgeon } \\
\hline$A$ & $32(17)$ & $32(17)$ & $64(17)$ & .99 & \\
\hline$B$ & $34(18)$ & $33(18)$ & $67(18)$ & & \\
\hline C & $50(26)$ & $46(25)$ & $96(25)$ & & \\
\hline$D$ & $46(24)$ & $49(26)$ & $95(25)$ & & \\
\hline Others & $31(16)$ & $28(15)$ & $59(16)$ & & \\
\hline \multicolumn{6}{|l|}{ Marital status } \\
\hline Never married & $3(1.6)$ & $3(1.6)$ & $6(1.6)$ & $.49 \dagger$ & \\
\hline Currently married & $150(77.7)$ & $150(79.8)$ & $300(78.7)$ & & \\
\hline Separated-divorced & $18(9.3)$ & $22(11.7)$ & $40(10.5)$ & & \\
\hline Widowed & $20(10.4)$ & $12(6.4)$ & $32(8.4)$ & & \\
\hline Living together & $1(0.5)$ & $1(0.5)$ & $2(0.5)$ & & \\
\hline Other & $1(0.5)$ & $0(0.0)$ & $1(0.3)$ & & \\
\hline \multicolumn{6}{|l|}{ Education } \\
\hline Not a high school graduate & $84(43.5)$ & $74(39.4)$ & $158(41.5)$ & .39 & \\
\hline High school/vocational/business/some college & $88(45.6)$ & $85(45.2)$ & $173(45.4)$ & & \\
\hline College graduate & $21(10.9)$ & $29(15.4)$ & $50(13.1)$ & & \\
\hline \multicolumn{6}{|l|}{ Smoking } \\
\hline Ever smoked regularly & $153(79)$ & $143(76)$ & $296(78)$ & & \\
\hline Currently smokes & $31(21)$ & $28(20)$ & $59(20)$ & & \\
\hline Height $(\mathrm{cm})$, mean (SD) & $175(9)$ & $173(10)$ & $174(10)$ & & \\
\hline Weight $(\mathrm{kg})$, mean (SD) & $84(18)$ & $81(16)$ & $174(10)$ & & \\
\hline Body mass index, mean (SD) & $27.4(5.2)$ & $27.3(4.6)$ & $83(17)$ & & \\
\hline
\end{tabular}

$S D$, Standard deviation. *Maximum number for each treatment arm; number varies by 1 because of missing values. All data are provided as number (percentage), except as noted. $†$ Some lumping (never + living together + other) to compute this $P$ value.

days, $37 \%$ vs $42 \%$ at $5.5-6.5$ weeks, and $22 \%$ vs $28 \%$ at 5.5-6.5 months, respectively).

\section{Discussion}

Administration of insulin during CPB failed to improve outcomes, as assessed by the combined incidence of neuroophthalmologic, neurologic, or neuropsychologic deficits or neurologic death in patients without diabetes mellitus undergoing CABG. Insulin administration failed to improve either short-term or long-term outcome and failed to reduce length of hospital stay. Moreover, in the control group, subjects with greater blood glucose measurements during CPB had no worse outcome than subjects with more nearly normal blood glucose measurements.
We were unable to completely prevent hyperglycemia during CPB, despite insulin infusion. It is likely that we would have achieved better glucose control had we administered larger doses of insulin in response to hyperglycemia. Studies completed after we initiated this protocol have shown that attempting complete glucose control during CPB might be hazardous because of the frequent postoperative hypoglycemia and hypokalemia that will result. ${ }^{14}$

Our selection of $100 \mathrm{mg} / \mathrm{dL}$ as our target value was based on the diabetes literature. Since the results of the Diabetes Control and Complications Trial were published, there has been an increased emphasis on avoidance of hyperglycemia in diabetic subjects. ${ }^{15}$ Our negative results do not argue 


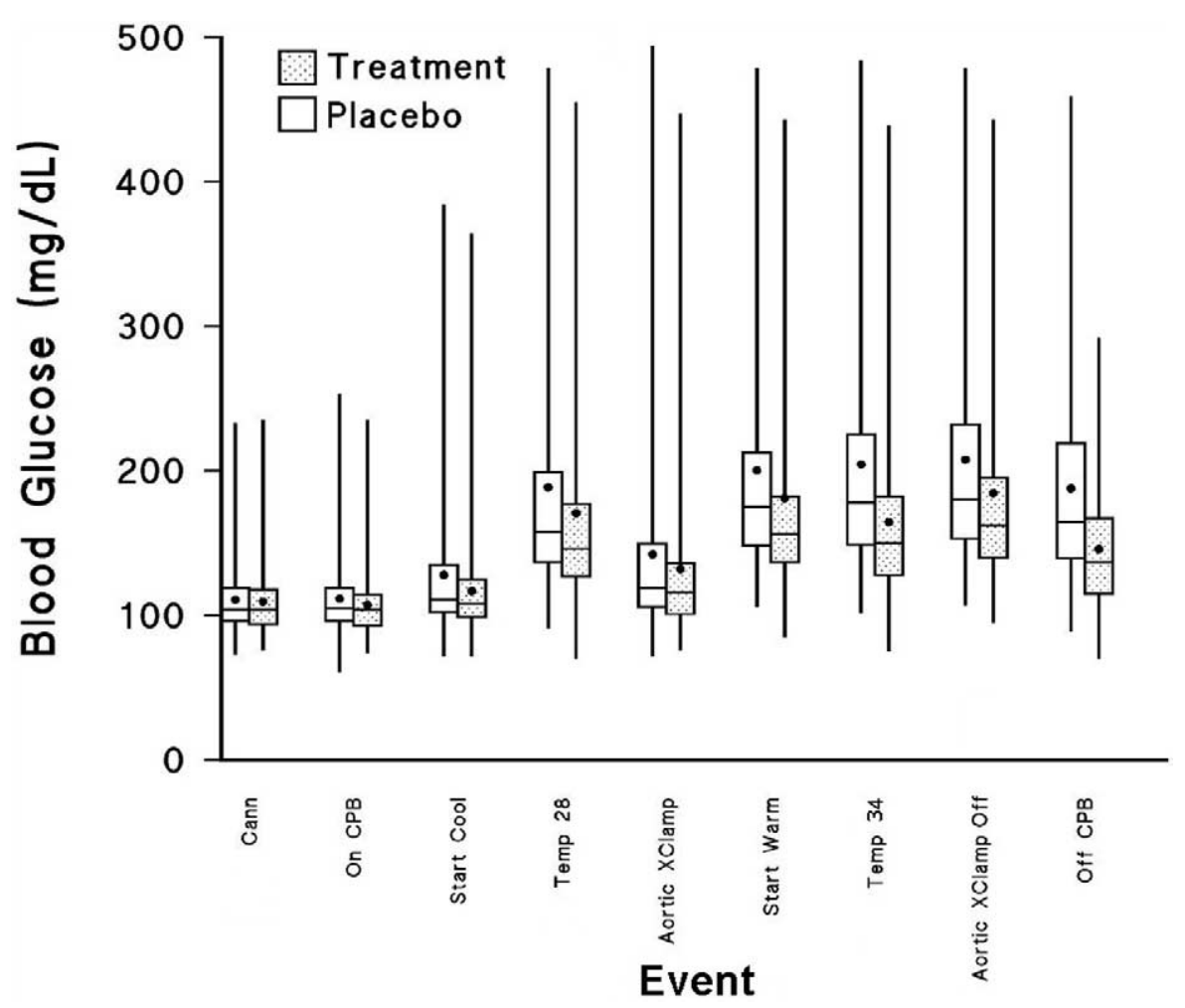

Figure 1. Box plots of blood glucose measurements in the 2 treatment groups at the time of various surgical events. The boxes include the 25 th to 75 th percentile values. The thicker lines denote the 50 th percentile value. The vertical lines define the 5th and 95th percentile values. The dot denotes the mean value. The insulin-treated group (shaded bars) had significantly $(P<.001)$ reduced blood glucose measurements during cardiopulmonary bypass (all measurements between "on CPB" and "X-clamp off," inclusive) compared with the control group (open bars) by a mixed-effects, repeated-measures model. Cann, Cannulation; on CPB, initiation of CPB; Start Cool, initiation of cooling; Temp 28, arrival of nasopharyngeal temperature at nadir of $28^{\circ} \mathrm{C}$; Aortic XClamp, application of aortic crossclamp; Start Warm, rewarming begins; Temp 34, nasopharyngeal temperature reaches $34^{\circ} \mathrm{C}$; Aortic XClamp Off, removal of aortic crossclamp; Off CPB, 5 minutes after separation from CPB.

against tight control of blood glucose before or after CPB ${ }^{16,17}$ Numerous studies have shown value in the control of hyperglycemia in patients undergoing $\mathrm{CABG}$ and with other critical illnesses. ${ }^{18-20}$ Some recent studies also demonstrate an association between hyperglycemia and adverse outcomes after ischemic stroke. ${ }^{21}$

Our data argue that blood glucose concentrations as great as $200 \mathrm{mg} / \mathrm{dL}$ do not appear to be deleterious during CPB in

TABLE 2. Adverse events by treatment arm

\begin{tabular}{lcccc}
\hline & $\begin{array}{c}\text { Placebo, } \\
\mathbf{n}(\%)\end{array}$ & $\begin{array}{c}\text { Insulin, } \\
\mathbf{n}(\%)\end{array}$ & $\begin{array}{c}\text { Total, } \\
\text { n (\%) }\end{array}$ & $\begin{array}{c}\text { Fisher exact test, } \\
\boldsymbol{P} \text { value }\end{array}$ \\
\hline Death & $5(2.6)$ & $6(3.2)$ & $11(2.9)$ & .77 \\
Stroke & $3(1.5)$ & $5(2.6)$ & $8(2.1)$ & .50 \\
Cardiac arrest requiring CPR & $1(0.5)$ & $3(1.6)$ & $4(1)$ & .37 \\
Arrhythmia requiring cardioversion & $4(2.1)$ & $2(1.1)$ & $6(1.6)$ & .69 \\
Hypoglycemia (blood glucose $<70 \mathrm{mg} / \mathrm{dL})$ & $12(6.2)$ & $22(11.7)$ & $34(8.9)$ & .07 \\
Hyperkalemia (K $>5.5 \mathrm{mEq} / \mathrm{L})$ & $44(22.7)$ & $35(18.6)$ & $79(20.7)$ & .38 \\
Rehospitalization & $28(16.2)$ & $19(11.6)$ & $47(13.9)$ & .27
\end{tabular}

$C P R$, Cardiopulmonary resuscitation. 
TABLE 3. Impaired performance on neuropsychologic testing (exceeding $20 \%$ of baseline) by treatment arm (\%)

\begin{tabular}{|c|c|c|c|c|c|c|}
\hline & \multicolumn{2}{|c|}{$4-8 \mathrm{~d}$} & \multicolumn{2}{|c|}{ 3-6 wk } & \multicolumn{2}{|c|}{ 5.5-6.5 mo } \\
\hline & $\begin{array}{c}\text { Placebo } \\
(\mathrm{n}=156)\end{array}$ & $\begin{array}{c}\text { Insulin } \\
(\mathbf{n}=152) \\
\end{array}$ & $\begin{array}{c}\text { Placebo } \\
(\mathrm{n}=166)\end{array}$ & $\begin{array}{c}\text { Insulin } \\
(\mathbf{n}=153) \\
\end{array}$ & $\begin{array}{l}\text { Placebo } \\
(\mathrm{n}=128)\end{array}$ & $\begin{array}{c}\text { Insulin } \\
(\mathrm{n}=121) \\
\end{array}$ \\
\hline Mean visual reaction & 38 & 31 & 16 & 16 & 21 & 18 \\
\hline Trails A & 28 & 29 & 11 & 13 & 15 & 12 \\
\hline Trails B & 37 & 40 & 9 & 14 & 10 & 9 \\
\hline \multicolumn{7}{|l|}{ Grooved Pegboard } \\
\hline Dominant hand & 27 & 36 & 2 & 7 & 1 & 3 \\
\hline Nondominant hand & 29 & 41 & 3 & 7 & 2 & 2 \\
\hline Symbol Digit & 30 & 23 & 3 & 3 & 3 & 3 \\
\hline Letter Cancellation & 36 & 25 & 10 & 13 & 4 & 4 \\
\hline \multicolumn{7}{|l|}{ Finger Tapping } \\
\hline Dominant hand & 12 & 15 & 5 & 5 & 3 & 2 \\
\hline Nondominant hand & 13 & 12 & 4 & 3 & 5 & 2 \\
\hline Nonverbal Memory & 12 & 15 & 7 & 7 & 7 & 6 \\
\hline Rey Auditory Verbal & 22 & 29 & 19 & 15 & 6 & 10 \\
\hline
\end{tabular}

nondiabetic patients. Thus, aggressive treatment does not appear to be warranted. These results and conclusions are consistent with an earlier study of glucose-insulin-potassium (GIK) during CABG. ${ }^{22}$

Nevertheless, our study has several obvious limitations. We made no attempt to control blood glucose concentrations at times other than CPB in these subjects who did not have diabetes. We hypothesized that brain injury associated with coronary surgery occurs mostly during $\mathrm{CPB}$, and we focused on control of blood glucose during that critical period. It very well could be important to control blood glucose concentrations after $\mathrm{CPB}$ in patients who have sustained a brain insult, and our results do not address that possibility. We also did not study patients having any of the several forms of "beating-heart" surgery without CPB, and our results might not apply to those patients. After this study was completed, our usual practice changed, and we no longer routinely cool patients who are undergoing CABG. It is possible that tight glucose control might offer greater benefit to patients having lesser degrees of hypothermic protection. On the other hand, a recent study of patients undergoing correction of congenital heart disease has shown no detrimental effect on outcome of increased intraoperative blood glucose concentrations. ${ }^{23}$

The most important limitation of our study is that we specifically excluded diabetic patients from our study, and therefore our results might not apply to that population. Diabetes is associated with worse outcomes after CABG. ${ }^{24}$ We suggest that insulin infusion should be used to control blood glucose concentrations in diabetic subjects undergoing CABG. Our exclusion of diabetic subjects led to a disproportionate reduction in the number of female subjects.

A recent study has compared tight glycemic control with infusion of GIK solution to intermittent subcutaneous injections of insulin in diabetic patients undergoing $\mathrm{CABG} .{ }^{25} \mathrm{In}$ this trial $30 \%$ of these diabetic patients were using insulin, and the remainder were using either oral agents or dietary adjustments for glucose control preoperatively. In this study GIK was discontinued on initiation of CPB and not restarted until the aorta was unclamped. In other words, it studied GIK at times

TABLE 4. New or worsening deficits by treatment arm and visit

\begin{tabular}{|c|c|c|c|c|c|}
\hline & Treatment arm & $\begin{array}{c}\text { 4-8 d, n } \\
(\%)\end{array}$ & $\begin{array}{c}\text { 3-6 wk, n } \\
(\%)\end{array}$ & $\begin{array}{c}\text { 5.5-6.5 mo, n } \\
(\%)\end{array}$ & $\begin{array}{c}\text { GEE treatment-time, } \\
P \text { value }\end{array}$ \\
\hline \multirow[t]{2}{*}{ Neuro-ophthalmologic } & Placebo & $14(8)$ & $5(3)$ & $5(4)$ & .714 \\
\hline & Insulin & $20(12)$ & $11(8)$ & $11(10)$ & \\
\hline \multirow[t]{2}{*}{ Neurologic } & Placebo & $42(24)$ & $30(20)$ & $7(6)$ & .062 \\
\hline & Insulin & $34(21)$ & $22(16)$ & $15(13)$ & \\
\hline \multirow[t]{2}{*}{ Neuropsychologic } & Placebo & $98(63)$ & $35(22)$ & $22(18)$ & .665 \\
\hline & Insulin & $98(65)$ & $31(21)$ & $16(13)$ & \\
\hline \multirow[t]{3}{*}{ Neurologic death } & Placebo & $120(67)$ & $62(39)$ & $31(25)$ & .5 \\
\hline & Insulin & $115(66)$ & $55(37)$ & $34(30)$ & \\
\hline & Combined & $235(67)$ & $117(38)$ & $65(27)$ & \\
\hline
\end{tabular}

All data are given as percentage incidence (no. of observations). 
when we did not infuse insulin and did not infuse GIK at the specific times we infused insulin. Moreover, this trial focused on those patients who were excluded from our study. Interestingly, the GIK group had a reduced incidence of atrial fibrillation, a shorter length of hospital stay, and a survival advantage compared with the control group.

Our outcome measures are similar to those used in other tests of neuroprotective drugs and neuroprotective strategies during cardiac surgery. ${ }^{26-28}$ Our selection of neuropsychologic tests was consistent with recommendations from consensus panels. ${ }^{29}$ Our criterion for neuropsychologic deficit defines a distinctly abnormal score for each subject on the basis of the subject's baseline performance. Because of learning-practice effects, it would be expected that healthy control subjects not having operations would show at worst the same score as at baseline and more often an improved score.

In conclusion, insulin infusion for attempted blood glucose control during CPB failed to improve either short-term or long-term neurologic outcomes, and it failed to shorten length of stay. Even though tight control of blood glucose concentration improves outcomes in many classes of patients with critical illness, attempted tight control of blood glucose with insulin infusion appears not to produce brain protection in patients undergoing CABG with CPB. Perhaps the opinion expressed in a recent editorial by Loepke and Spaeth, ${ }^{30}$ that children are unlike adults in the failure of hyperglycemia to worsen outcome, might be incorrect. It might be that neither adults nor children derive benefit from strategies to prevent mild intraoperative hyperglycemia in patients who do not have diabetes mellitus.

\section{References}

1. Roach GW, Kanchuger M, Mangano CM, et al. Adverse cerebral outcomes after coronary bypass surgery. Multicenter Study of Perioperative Ischemia Research Group and the Ischemia Research and Education Foundation Investigators. N Engl J Med. 1996;335:1857-63.

2. Newman SP, Stygall J. Neuropsychological outcome following cardiac surgery. In: Newman SP, Harrison MJG, editors. The brain and cardiac surgery. The causes of neurological complications and their prevention. Amsterdam: Overseas Publishers Association; 2000. p. 21-50.

3. Grocott HP, Laskowitz DT, Newman MF. Markers of cerebral injury. In: Newman SP, Harrison MJG, editors. The brain and cardiac surgery. The causes of neurological complications and their prevention. Amsterdam: Overseas Publishers Association; 2000. p. 113-42.

4. Chew W, Kucharczyk J, Moseley M, Derugin N, Norman D. Hyperglycemia augments ischemic brain injury: in vivo MR imaging/spectroscopic study with nicardipine in cats with occluded middle cerebral arteries. AJNR Am J Neuroradiol. 1991;12:603-9.

5. Challa VR, Moody DM, Troost BT. Brain embolic phenomena associated with cardiopulmonary bypass. J Neurol Sci. 1993;117:224-31.

6. Groban L, Butterworth J, Legault C, Rogers AT, Kon ND, Hammon JW. Intraoperative insulin therapy does not reduce the need for inotropic or antiarrhythmic therapy after cardiopulmonary bypass. $J$ Cardiothorac Vasc Anesth. 2002;16:405-12.

7. Smith MH, Wagenknecht LE, Legault C, et al. Age and other risk factors for neuropsychologic decline in patients undergoing coronary artery bypass graft surgery. J Cardiothorac Vasc Anesth. 2000;14:428-32.

8. Neville MJ, Butterworth J, James RL, Hammon JW, Stump DA. Similar neurobehavioral outcome after valve or coronary artery oper- ations despite differing carotid embolic counts. $J$ Thorac Cardiovasc Surg. 2001;121:125-36.

9. Kunitz SC, Gross CR, Heyman A, et al. The pilot Stroke Data Bank: definition, design, and data. Stroke. 1984;15:740-6.

10. Shaw PJ, Bates D, Cartlidge NE, et al. Neurologic and neuropsychological morbidity following major surgery: comparison of coronary artery bypass and peripheral vascular surgery. Stroke. 1987;18:700-7.

11. Harrison MJ, Schneidau A, Ho R, Smith PL, Newman S, Treasure T. Cerebrovascular disease and functional outcome after coronary artery bypass surgery. Stroke. 1989;20:235-7.

12. O'Brien PC, Fleming TR. A multiple testing procedure for clinical trials. Biometrics. 1979;35:549-56.

13. Lan KKG, Simon R, Halperin M. Stochastically curtailed tests in long-term clinical trials. Communications in Statistics: Sequential Analysis. 1982;1:207-219.

14. Chaney MA, Nikolov MP, Blakeman BP, Bakhos M. Attempting to maintain normoglycemia during cardiopulmonary bypass with insulin may initiate postoperative hypoglycemia. Anesth Analg. 1999;89:1091-5.

15. Diabetes Control and Complications Trial Research Group. The effect of intensive treatment of diabetes on the long term complications in insulin dependent diabetes mellitus. N Engl J Med. 1993;329:977-86.

16. Murkin JM. Pro: tight intraoperative glucose control improves outcome in cardiovascular surgery. J Cardiothorac Vasc Anesth. 2000; 14:475-8.

17. DeBrouwere R. Con: tight intraoperative glucose control does not improve outcome in cardiovascular surgery. $J$ Cardiothorac Vasc Anesth. 2000;14:479-81.

18. Furnary AP, Zerr KJ, Grunkemeier GL, Starr A. Continuous intravenous insulin infusion reduces the incidence of deep sternal wound infection in diabetic patients after cardiac surgical procedures. Ann Thorac Surg. 1999;67:352-62.

19. Estrada CA, Young JA, Nifong LW, Chitwood WR Jr. Outcomes and perioperative hyperglycemia in patients with or without diabetes mellitus undergoing coronary artery bypass grafting. Ann Thorac Surg. 2003;75:1392-9.

20. van den Berghe G, Wouters P, Weekers F, et al. Intensive insulin therapy in the critically ill patients. N Engl J Med. 2001;345:1359-67.

21. Bruno A, Biller J, Adams HP Jr, et al. Acute blood glucose level and outcome from ischemic stroke. Trial of ORG 10172 in Acute Stroke Treatment (TOAST) Investigators. Neurology. 1999;52:280-4.

22. Lazar HL, Philippides G, Fitzgerald C, et al. Glucose-insulin-potassium solutions enhance recovery after urgent coronary artery bypass grafting. J Thorac Cardiovasc Surg. 1997;113:354-62.

23. de Ferranti S, Gauvreau K, Hickey PR, et al. Intraoperative hyperglycemia during infant cardiac surgery is not associated with adverse neurodevelopmental outcomes at 1, 4, and 8 years. Anesthesiology. 2004;100:1345-52.

24. Carson JL, Scholz PM, Chen AY, Peterson ED, Gold J, Schneider SH. Diabetes mellitus increases short-term mortality and morbidity in patients undergoing coronary artery bypass graft surgery. $\mathrm{J}$ Am Coll Cardiol. 2002;40:418-23.

25. Lazar HL, Chipkin SR, Fitzgerald CA, Bao Y, Cabral H, Apstein CS. Tight glycemic control in diabetic coronary artery bypass graft patients improves perioperative outcomes and decreases recurrent ischemic events. Circulation. 2004;109:1497-502.

26. Legault C, Furberg CD, Wagenknecht LE, et al. Nimodipine neuroprotection in cardiac valve replacement: report of an early terminated trial. Stroke. 1996;27:593-8.

27. Kong RS, Butterworth J, Aveling W, et al. Clinical trial of the neuroprotectant clomethiazole in coronary artery bypass graft surgery: a randomized controlled trial. Anesthesiology. 2002;97:585-91.

28. Wang D, Wu X, Li J, Xiao F, Liu X, Meng M. The effect of lidocaine on early postoperative cognitive dysfunction after coronary artery bypass surgery. Anesth Analg. 2002;95:1134-41.

29. Murkin JM, Newman SP, Stump DA, Blumenthal JA. Statement of consensus on assessment of neurobehavioral outcomes after cardiac surgery. Ann Thorac Surg. 1995;59:1289-95.

30. Loepke AW, Spaeth JP. Glucose and heart surgery: neonates are not just small adults. Anesthesiology. 2004;100:1339-41. 
TABLE E1. Contents of cardioplegic solutions

\begin{tabular}{|c|c|c|c|c|}
\hline & \multicolumn{2}{|c|}{ Induction dose } & \multicolumn{2}{|c|}{ Subsequent doses } \\
\hline \multicolumn{5}{|c|}{ Blood cardioplegia* } \\
\hline THAM & $2.1 \mathrm{~g}$ & $71.6 \mathrm{~mL}$ & $1.6 \mathrm{~g}$ & $53.3 \mathrm{~mL}$ \\
\hline Glutamate & $32.4 \mathrm{~g}$ & $44.3 \mathrm{~mL}$ & $24.4 \mathrm{~g}$ & $33.3 \mathrm{~mL}$ \\
\hline Aspartate & $27.7 \mathrm{~g}$ & $44.3 \mathrm{~mL}$ & $20.8 \mathrm{~g}$ & $33.3 \mathrm{~mL}$ \\
\hline CPD & & $17.8 \mathrm{~mL}$ & & $13.3 \mathrm{~mL}$ \\
\hline $\mathrm{KCl}$ & $26.6 \mathrm{mEq}$ & $13.3 \mathrm{~mL}$ & $0.0 \mathrm{mEq}$ & $0.0 \mathrm{~mL}$ \\
\hline Lidocaine & $50.0 \mathrm{mg}$ & $2.5 \mathrm{~mL}$ & $50.0 \mathrm{mg}$ & $2.5 \mathrm{~mL}$ \\
\hline \multirow[t]{2}{*}{$D_{5} W$} & & $88.1 \mathrm{~mL}$ & & $66.8 \mathrm{~mL}$ \\
\hline & & $282.5 \mathrm{~mL}$ & & $202.5 \mathrm{~mL}$ \\
\hline \multicolumn{5}{|c|}{ Cystalloid cardioplegia } \\
\hline$D_{5} L R$ & \multicolumn{2}{|c|}{$1000 \mathrm{~mL}$} & \multicolumn{2}{|c|}{$1000 \mathrm{~mL}$} \\
\hline $\mathrm{NaHCO}_{3}$ & \multicolumn{2}{|c|}{$25 \mathrm{mEq}$} & \multicolumn{2}{|c|}{$25 \mathrm{mEq}$} \\
\hline Heparin & \multicolumn{2}{|c|}{$2000 \mathrm{U}$} & \multicolumn{2}{|c|}{$2000 \mathrm{U}$} \\
\hline $\mathrm{KCl}$ & \multicolumn{2}{|c|}{$25 \mathrm{mEq}$} & \multicolumn{2}{|c|}{$10 \mathrm{mEq}$} \\
\hline
\end{tabular}

THAM, Tris-hydroxyaminomethane; $C P D$, citrate-phosphate-dextrose; $D_{5} W, 5 \%$ dextrose in water; $D_{5} L R, 5 \%$ dextrose in lactated Ringer's solution. *Blood cardioplegic solutions were mixed 1:4 with heparinized blood before administration.

TABLE E2. Baseline neuropsychologic assessment scores by treatment arm

\begin{tabular}{|c|c|c|c|}
\hline Test & $\begin{array}{c}\text { Placebo } \\
(\mathrm{n}=193)^{*}\end{array}$ & $\begin{array}{c}\text { Insulin } \\
(\mathbf{n}=188)^{*}\end{array}$ & $\begin{array}{c}\text { All } \\
(n=381)\end{array}$ \\
\hline Visual reaction time (s) & $1.6(0.9)$ & $1.6(0.8)$ & $1.6(0.9)$ \\
\hline Trails A corrected time (s) & $62(23)$ & $61(22)$ & $62(22)$ \\
\hline Trails B corrected time (sec) & $127(50)$ & $122(48)$ & $124(49)$ \\
\hline \multicolumn{4}{|l|}{ Grooved Pegboard total time $(\mathrm{s})$} \\
\hline Dominant hand & $93(31)$ & $90(27)$ & $92(29)$ \\
\hline Nondominant hand & $101(29)$ & $95(26)$ & $98(28)$ \\
\hline Symbol Digit total time (s) & $214(52)$ & $211(53)$ & $213(52)$ \\
\hline Letter Cancellation total time (s) & $136(37)$ & $137(37)$ & $137(37)$ \\
\hline \multicolumn{4}{|l|}{ Finger Tapping (mean no. of taps) } \\
\hline Dominant hand & $32(8)$ & $32(8)$ & $32(8)$ \\
\hline Nondominant hand & $29(7)$ & $29(7)$ & $29(7)$ \\
\hline Nonverbal memory (total correct) & $16(3)$ & $16(3)$ & $16(3)$ \\
\hline Rey Auditory Verbal (total score) & $46(13)$ & $48(13)$ & $47(13)$ \\
\hline
\end{tabular}

*Maximum $\mathrm{n}$ for each treatment arm; $\mathrm{n}$ varies by no more than 6 because of missing values (except for Trails $\mathrm{B}$, in which $\mathrm{n}=175$ for arm 1 and $\mathrm{n}=173$ for arm 2, and for Rey, in which $n=175$ for arm 1 and $n=174$ for arm 2). 
TABLE E3. Baseline distribution of preoperative neurologic and neuro-ophthalmologic abnormalities by treatment arm

\begin{tabular}{lccc}
\hline No. of abnormalities & $\begin{array}{c}\text { Placebo } \\
(\mathbf{n}=\mathbf{1 8 8}), \%\end{array}$ & $\begin{array}{c}\text { Insulin } \\
(\mathbf{n}=\mathbf{1 8 5}), \%\end{array}$ & $\begin{array}{c}\text { All } \\
(\mathbf{n}=\mathbf{3 7 3}), \%\end{array}$ \\
\hline Neurologic & & & \\
0 & $147(78.2)$ & $156(84.3)$ & $303(81.2)$ \\
1 & $36(19.2)$ & $26(14.1)$ & $62(16.6)$ \\
2 & $5(2.7)$ & $2(1.1)$ & $7(1.9)$ \\
3 & $0(0.0)$ & $1(0.5)$ & $1(0.3)$ \\
Neuro-ophthalmologic & & & \\
0 & $168(89.4)$ & $164(89.6)$ & $332(89.5)$ \\
1 & $18(9.6)$ & $19(10.4)$ & $37(10.0)$ \\
2 & $2(1.1)$ & $0(0.0)$ & $2(0.5)$ \\
\hline
\end{tabular}

